\title{
Consciousness and representation
}

Denis Seron (FNRS - University of Liège, Belgium)

d.seron@uliege.be

D. Seron (2021). Consciousness and representation. In: Franz Brentano's Philosophy after One Hundred Years - From History of Philosophy to Reism (D. Fisette, G. Fréchette, H. Janoušek, Eds.). Springer, pp. 41-53.

Draft version.

A common interpretation of Brentano's theory of consciousness is the so-called selfrepresentational interpretation. According to this interpretation, Brentano in the Psychology conceived of consciousness as a form of representation or intentional act. This reading seems to find strong support in the text. In a famous passage from the Psychology, Brentano clearly defends the view that the act of hearing a sound has two distinct objects, namely the sound as a physical phenomenon and the act of hearing as a mental phenomenon. This seems to suggest that, as some commentators claim, Brentano ascribes to every mental act two distinct intentions, namely a primary intention that is directed towards a physical phenomenon and a secondary intention that is directed towards itself, that is, towards a mental phenomenon. Since it is a unique mental act that is directed both inwards and outwards, the distinction between the two intentions must be, as Brentano argues, not a real but an abstract or conceptual distinction. Accordingly, Brentano's view that every mental act is conscious means that every mental act exhibits a partial intention which relates to the mental act itself. And from this it can be concluded that consciousness or inner perception is essentially representational.

The self-representational interpretation was much debated in the last fifteen years. Some authors simply reject it, while others agree that Brentano was a self-representationalist but claim that Brentano was wrong and that consciousness is better described as a non-intentional or "pre-reflective" self-awareness, as in Husserl and Sartre. The present chapter has two distinct aims. The first one is to offer two new objections on the basis of what could be called a phenomenological approach to intentionality and consciousness. My contention is that the self-representational interpretation is untenable simply because, for Brentano, a representational perception is conceptually impossible. The second aim is to provide a relatively new construal of Brentano's theory of secondary objects. 


\section{Preliminary remarks}

The core of the self-representational interpretation is what Uriah Kriegel calls Brentano's "most striking thesis", namely: "There could be no representation without self-representation" (Kriegel 2013: 24). "Self-representation" here is supposed to be equivalent to "consciousness". The question I want to address is this: Is consciousness for Brentano really a self-representation? Is it intrinsically intentional as self-representationalists claim?

As is well-known, Brentano himself did not use the word "intentionality". Nor did he use the word "intentional" in the contemporary sense of "directed toward something". This makes it desirable, as a first step, to identify what corresponds to now so-called "intentionality" in Brentano's philosophy of mind, or what he would have called "intentionality" if he had used the word.

I think we can safely agree that what Brentano would have called "intentionality" must meet at least these five conditions:

(1) First, instead of "intentionality", Brentano uses the terms "relation to a content", "relation to an object", or "direction toward an object" (Richtung auf ein Objekt) (Brentano 1973: 124; Engl. trans. 88). Intentionality is a two-term relation one term of which is an object or content.

(2) Secondly, a content is something that is contained within what it is the content of. As Brentano claims in a famous passage of the Psychology: "Every mental phenomenon includes something as object within itself" (Brentano 1973: 125; Engl. trans. 88). In other words: intentionality is somehow a part-whole relation.

(3) In the 1911 Appendix, Brentano puts the matter otherwise by saying that intentionality is a "mental relation" (psychische Beziehung) (Brentano 1925: app. 1). This is my third condition. A mental relation, as I understand the term, is a relation that has no existence except in the mind - a relation such that accepting it as existent does not commit you to accepting as existent anything outside the mind. Today this position is labeled "internalism".

(4) Fourthly, it is evident that the term "mental relation" should not be taken to denote a metaphysical relation - a relation that has something to do with the soul. The relata are only appearances in the mind, namely mental and physical phenomena. In this sense, intentionality could be called a phenomenal relation, or an "apparent directedness" as Katalin Farkas once suggested (Farkas 2013). An apparent or phenomenal relation is something that appears to be a relation but is not a real relation. For example, neither Donald Duck nor his sailor shirt really exist and the sentence "Donald Duck wears a sailor shirt" does not denote a real relation. Yet this relation is imagined and the sentence is true: it is true that Disney used to draw Donald Duck with a sailor shirt and that well-informed people normally imagine Donald Duck with a sailor shirt. The relation is something that appears in the mind - and it is true 
that it appears in the mind.

(5) This leads us to the fifth and final requirement. Every real relation is such that necessarily, if it exists, all its relata exist. If intentionality were a real relation, that is, a relation that really exists, then fictions, hallucinations and false judgments would not be intentional. But intentionality, as we have seen, is not a real relation. Therefore, as Brentano says:

If someone thinks of something, the one who is thinking must certainly exist, but the object of his thinking need not exist at all. (...) So the only thing which is required by mental relation is the person thinking. The terminus of the so-called relation does not need to exist in reality at all. (Brentano 1925: 134; Engl. trans. 272)

To put it otherwise: Intentionality, as an apparent relation, cannot appear unless the represented object appears. Appearing, however, does not entail really existing. The intentional relation can obtain even when the represented object does not exist.

It would be a mistake to interpret the above quote as being about what we today call "representational opacity". Brentano's claim here is not only that the represented object can possibly not exist. His claim, as I understand it, is that the represented object cannot possibly exist or that it necessarily does not exist. This claim can be called the intentional existence claim. Necessarily every intentional object or content is such that it exists only intentionally or phenomenally (as Brentano also says). In other words: it is something that appears in the mind, a phenomenon, but it does not really exist. This is part of the definition of the concept of intentionality that is commonly attributed to Brentano in the Psychology. The word "object", Brentano claims, "is not to be understood here as meaning a reality" (Realität) (Brentano 1973: 124-125).

A clear illustration of this is provided by Brentano's account of Kant's one hundred thalers example in the 1911 Appendix (Brentano 1925: 136; Engl. trans. 274). Kant said that a hundred actual thalers are not more than a hundred possible or conceived thalers. To this Brentano replies that a hundred real thalers are much more than a hundred conceived thalers. Actually, they are one hundred thalers more than a hundred conceived thalers. The hundred conceived thalers are "not a sum of money at all, and indeed do not exist at all". Intentional thalers, like all other intentional objects, do not exist. Of a man who owes only intentional money, we will legitimately say that he is penniless.

The five conditions I have laid out are what I consider to be the most important characterizations of intentionality according to Brentano. What contemporary philosophers call "intentionality" corresponds, in Brentano, to this: a phenomenal and mereological relation to a content or object that does not exist. 
The question now before us is this: Does the "secondary intention" talked about by selfrepresentationalists meet these five conditions? If so-called "secondary intention" is to fulfil all the five conditions, then there will be good reason to think that it is, as selfrepresentationalists claim, a representation in the contemporary sense of the word. It won't be thereby proven to be representational, for the conjunction of the five conditions may be a necessary but not sufficient condition. Nevertheless, we will then have a good argument in favor of the self-representational interpretation of Brentano's theory of consciousness. In the converse case, namely if we manage to prove that so-called "secondary intention" does not meet the five conditions for there being intentionality, then we will have proved that the selfrepresentational interpretation is false.

\section{Two difficulties of the self-representational reading}

My opinion is that what some commentators call a "secondary intention" is not an intention at all and thus that Brentano was not a self-representationalist. In order to establish this, I will try to show that so-called "secondary intention" is not a phenomenal and mereological relation to a content or object that does not exist. Since I do not believe that so-called "secondary intention" is really an intention, I will rather use the term "secondary relation", which is used by Brentano himself in the 1911 Appendix (Brentano 1925: 139).

In my view, the self-representational interpretation gives rise to at least two major problems.

(A) The first issue to be considered is about the fifth condition above, namely intentional existence.

In Brentano's view, the intentional object is something that does not really exist. This applies to veridical representations as well. When you look at the color of the table, the phenomenal color you see is something that appears in your mind, but obviously there exists nothing in your mind that can be called a color.

Now let us consider the secondary relation. If the self-representational interpretation is correct, then the secondary relation is a representation, that is, something that relates the mental act to an intentional content - namely to itself. This content either really exists or does not really exist. But if it really exists, then the secondary relation does not fulfil the fifth condition for being intentional and hence it is not a representation. Therefore, the selfrepresentational reading is necessarily false.

Accordingly, a self-representationalist reader of Brentano must suppose that the content of the secondary relation does not really exist. The mental act, like the color of the table, appears without really existing. But this option, too, leads to a contradiction. Indeed, the secondary relation is what Brentano more commonly calls "consciousness" or "inner perception". The 
self-representational view is that consciousness or inner perception is a kind of representation. Now, in Brentano's view, it is part of the definition of perception that its object really exists in the present. As opposed to being remembered or imagined, being perceived analytically implies real existence. And of course this applies to consciousness: being conscious means being "conscious of a mental phenomenon while it exists in us" (während es in uns besteht) (Brentano 1973: 176; Engl. trans. 126 slightly modified). In consequence, the view that the secondary relation is both an intention and an inner perception is self-contradictory.

In fact, it would suffice to say that the notion of a representational inner perception involves contradiction. If the represented object cannot exist, then the intentional relation cannot be reflexive. If a self-representation is a representation that is numerically identical with its object, then it is trivially impossible that there exists a self-representation whose object does not exist. And it is plausibly for this reason that Brentano claims that consciousness is a perception, that is, a presentation that gives an object as really existing in the present. ${ }^{1}$

To summarize: The content of a self-representational consciousness must exist and not exist at the same time. This suggests that the view that consciousness is self-representational is necessarily false.

(B) My second set of objections is related to condition (2), namely: intentionality is a partwhole relation.

By contrast with the higher-order interpretation, the self-representational interpretation centrally claims that the primary and the secondary relations are part of one single mental act. One and the same representation is directed toward both a physical and a mental phenomenon. This is necessary because, according to Brentano, all mental acts are necessarily conscious representations.

First, it should be remarked that this view sounds somewhat strange when applied to Brentano's theory of intentionality. Apart from the passage on secondary objects in the Psychology, Brentano always speaks of a "relation to $a$ content" and never of a relation to two contents.

Moreover, the idea of a single intentional act with two distinct contents is very counterintuitive. Supposing that consciousness is self-representational, it would be more natural to say that the mental act has one single object which is composed of two different parts, for example that color and the act of seeing that color. In a sense, this is how some selfrepresentationalists describe the content of the conscious representation. They see it as a

\footnotetext{
${ }^{1}$ Of course, it remains possible to advocate a wider concept of intentionality which includes self-presentations and allows infallible representations, i.e., representations such that, if they exist, then their object must exist. But this concept would fit with neither Brentano's nor the contemporary use of "intentional".
} 
unique phenomenal field with a focal and a peripheral area. The seen color occupies the focal center while the self-represented act is at the margin (Kriegel 2009).

Brentano, however, does not see things this way. He strongly affirms that there is a real distinction between the primary and the secondary object. That is why he sometimes presented himself as a dualist, in opposition to Ernst Mach's psychophysical identity thesis (Brentano 1988: 47-48; Seron, forthcoming). His claim is that one and the same mental act has two really distinct objects. We can correspondingly distinguish between a primary and a secondary presentation, but this latter distinction is not a real distinction. It is just an abstract or conceptual distinction: in reality there is only one mental act.

This raises a major difficulty for the self-representational reading. For the idea of a unique mental act with two objects is very problematic if the primary and secondary relations are representations. Suppose that self-representational readers are right and that every mental act includes within itself, say, two partial representations - a primary and a secondary intentions. For example, you represent both the color and your representation of the color at the same time. Thus, the two objects of your total representation are a physical phenomenon and a mental phenomenon. The actual picture, however, is a bit more complex. It is well-known that, in Brentano's view, "every mental phenomenon includes something as object within itself" (Brentano 1973: 125; Engl. trans. 88). Therefore, the objects of the total representation are, more precisely, the color and your act of seeing with its content - that is, your act of seeing qua something of which the color is a part. In other words: you represent the color and the act of seeing along with its content, namely the color. As a result, the color must be represented twice.

The problem is that Brentano very explicitly rejects the view that the physical phenomenon is (re)presented twice (see Textor 2006: 7 ff.). We might be tempted to say, Brentano argues,

that we have several presentations and that they are of different kinds; so much so that one of them constitutes the content of another, while having a physical phenomenon as its own content. If this were true, the physical phenomenon must, to a certain extent, belong to the content of both of these presentations, to that of one as its external object, to that of the other as, so to speak, its included object. It would seem, therefore, as Aristotle also noted, to turn out that the physical phenomenon must be presented twice. Yet this is not the case. (Brentano 1973: 178-179; Engl. trans. 127)

\section{A non-representational reading}

In the second part of this chapter, I would like to suggest a different construal of Brentano's 
theory of secondary objects, namely a construal in non-representational terms.

What is the idea behind Brentano's theory of secondary objects? In a nutshell, the general thought is this: Necessarily every single mental act has two really distinct objects, namely a primary and a secondary object. The former is for example the seen color; the latter is the act of seeing the color. For the sake of clarity, we certainly can regard these two objects as objects of two distinct Vorstellungen. The distinction between the two corresponding Vorstellungen, however, is just an abstract or conceptual distinction. If we adopt such an abstract distinction, then we can say that consciousness is the Vorstellung of the mental act's secondary object.

To begin with, let us ask what a Vorstellung is. The view I argued for in the first part is that a Vorstellung, in Brentano's terminology, is not a representation in the contemporary sense of the word. In short: being a Vorstellung does not involve having an intentional content. ${ }^{2}$ Accordingly, I will translate Vorstellung as "presentation" rather than "representation". It is worth noticing that this very common distinction between presentation and representation is accepted even by the defenders of the self-representational interpretation (Kriegel 2013: 24).

What is a presentation for Brentano? The answer is fairly easy to find. Brentano himself clearly indicates what a presentation is in the following quotes:

As we use the verb "to present", "to be presented" means the same as "to appear". (Brentano 1973: 114; Engl. trans. 81)

We speak of a presentation whenever something appears to us. (Brentano 1925: 34; Engl. trans. 198)

Wherever something appears, i.e., is given to us in consciousness, we talk of a presentation. (Brentano, F., 1956, p. 32).

To be presented simply means to appear, that is, to be a phenomenon. That's all. All physical

\footnotetext{
${ }^{2}$ One may object that this interpretation conflicts with the fact that Brentano uses intentionality as a "mark of the mental". The objection is as follows: Brentano undeniably holds that a given phenomenon is mental if, and only if, it has an intentional content (Seron 2015b), and that presentations are mental phenomena; therefore, in his view, every presentation must have an intentional content — which does not fit with my claim that for Brentano some presentations have no intentional content. But this objection is beside the point. My claim here is that for Brentano only primary presentations are intrinsically representational, that is, have an intentional content. By contrast, secondary presentations — one's acquaintance with one's own mental life — are not representational in nature. Now, Brentano strongly emphasizes that a secondary presentation with no primary presentation is impossible (Brentano 1973: 180; Engl. trans. 128). Since Brentano considers a mental act without presentation to be impossible, it follows from this that, for him, every mental act must contain as its part a primary presentation. Since every primary presentation must have an intentional content, every mental act must therefore have an intentional content. In consequence, the interpretation here proposed is fully consistent with Brentano's view that a given phenomenon is mental if, and only if, it has an intentional content.
} 
and mental phenomena must be presented, insofar as they are phenomena. Tim Crane (2017: 45) rightly claims that "presentation, for Brentano, is the fundamental way of being conscious of an object". Your being conscious of an object A means both that A appears to you and that you have a presentation of $\mathrm{A} .^{3}$

On the basis of this, we now can summarize Brentano's theory of secondary objects in terms of mental or physical phenomena rather than in terms of presentations. The idea is this: When you see a color, that is, when you experience the act of seeing a color, what appears to you or what you have a presentation of - is a combination of a physical and a mental phenomenon, namely the seen color and the act of seeing the color. As I said, the distinction between the physical and the mental phenomenon is a real distinction, while the distinction between primary and secondary presentation is only an abstract or conceptual distinction.

Your act of seeing the color has two really distinct objects, namely a mental and a physical phenomenon. However, this does not mean that your mental act has these two phenomena as its intentional objects. Actually, this would be impossible, for the mental phenomenon must exist and an intentional object, as we have seen, is something that does not exist. The mental phenomenon is, so to speak, the real object of your act, while the physical phenomenon is its intentional object. As Husserl puts it in the Logical Investigations, the difference is between the real and the intentional content of the act (Husserl 1984: 411 ff.; Engl. trans. 112 ff.).

Let me now propose a working hypothesis. This hypothesis is about a distinction which is not explicitly found in the first volume of the Psychology, namely the distinction between direct and oblique presentation. The act of seeing that color has two really distinct objects, namely a mental and a physical phenomenon, and to these two phenomena correspond two conceptually distinct presentations. My hypothesis is that this conceptual distinction between two kinds of presentation is, at least to some extent, one and the same as the distinction between direct and oblique presentation. More precisely: all secondary presentations are direct presentations; all primary presentations are oblique presentations. When you see the color, you have a direct presentation of your mental act, and an oblique presentation of the color. Since only mental phenomena can be objects of a secondary presentation, it follows from this that all physical phenomena are obliquely presented.

For Brentano, as we have seen, "being presented" means appearing or being a phenomenon. If my working hypothesis is correct, we can thus say that the oblique presentation of the color is the appearance of something that does not really exist. That a color is obliquely presented to you simply means that something, a color, appears in your mind without existing. You see a

\footnotetext{
${ }^{3}$ This suggests a significant distinction between Brentano's presentations and the British empiricists' "ideas" (Crane 2017: 45). See also (Stout 1896: 41): “Brentano's 'object' is the same as Kant's 'presentation'. It is an appearance in consciousness. It is what Brentano would call a content (Inhalt) of presentation."
} 
color that is a mere appearance. Since all physical phenomena are obliquely presented, this entails that no physical phenomenon really exists. As Brentano claims: "The objects of the socalled external perception... demonstrably do not exist outside of us. In contrast to that which really and truly exists, they are mere phenomena" (Brentano 1973: 14; Engl. trans. 10).

By contrast, as suggested earlier, the direct presentation of the mental act to itself necessarily involves real existence. That is why Brentano calls consciousness a "perception". A perception is by definition an act that involves acquaintance with things that really exist in the present. ${ }^{4}$ Thus, there is on the one side an oblique presentation of an intentional object, namely of something that appears without existing, on the other side a direct presentation of a real object, namely of a mental act that appears and really exists. It follows from what I said before that this distinction between the direct presentation of the act of seeing and the oblique presentation of the seen color is identical with the distinction between what Brentano calls "consciousness" and what he would have called "intentionality" if he had used the word.

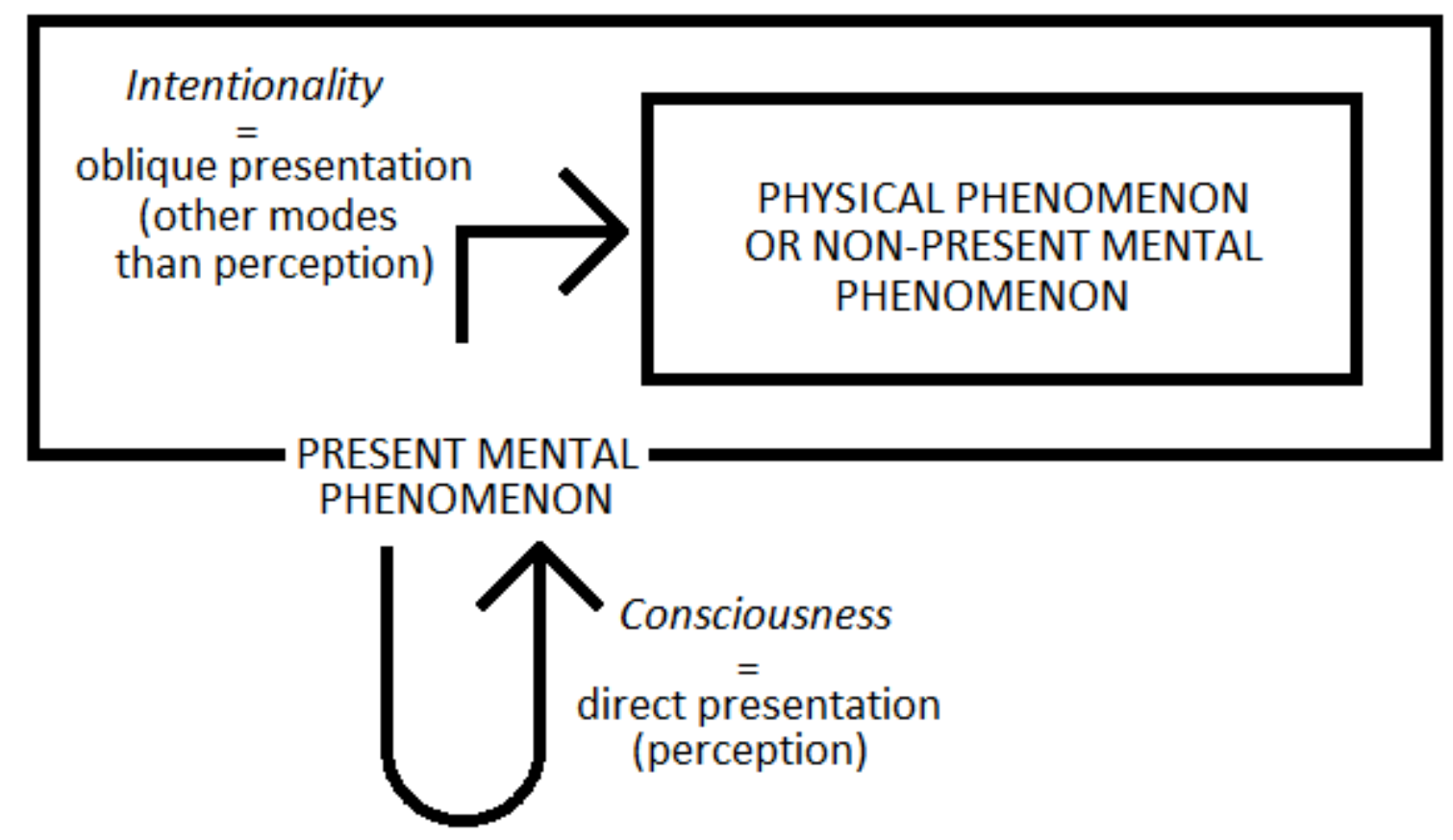

\footnotetext{
${ }^{4}$ Brentano's view of inner perception, thus construed, may in some ways seem close to Russell's view of acquaintance. As opposed to knowledge by description, acquaintance by definition requires an object that really exists (Russell 1992: 48 ff.). In what follows, I suggest that Brentano's presentism leads to an even stronger view, namely: For all $x, x$ really exists if, and only if, $x$ is perceived. (Needless to say, this view in itself does not rule out the existence of perceived mind-independent entities and is entirely consistent with realism.) Another significant difference is that Brentano's oblique mode is not restricted to conceptual thoughts and thus allows a nonconceptualist account of intentionality.
} 
A consequence of this is that not all presentations - not all acts of the first class - are representational. Only primary presentations are representational, while secondary presentations are directed toward an object that really exists and hence do not fulfil condition (5) in our list. One may be tempted to object that for Brentano every mental act is intentional, and that secondary presentations are obviously mental. But the objection would fail, because, in Brentano's view, the secondary presentation is not by itself a mental act. For there to be a mental act, there must be both a primary and a secondary presentation. Brentano regards the idea of a secondary presentation without primary presentation as self-contradictory: "A presentation of the act of hearing without a presentation of the sound would be an obvious contradiction" (Brentano 1973: 180; Engl. trans. 128).

Another consequence of what I said is that the intentional content is not, properly speaking, an abstract part of the mental act - although it certainly is necessarily dependent on the mental act inasmuch as a phenomenon is by definition something that is in the mind. The primary and the secondary presentation are abstract parts of the act insofar as there is no real distinction between them. By contrast, there is a real distinction between the primary and the secondary object.

What would Brentano have called "intentionality" if he had used the word? What he would have called "intentionality" is a combination of three features that are necessarily present in all mental acts. First, two really distinct phenomena appear to you or you have a presentation of two really distinct phenomena. Second, these two phenomena are such that one appears in the other, i.e., is the content of the other. Third, they are such that the containing phenomenon really exists and its content does not. In short, what Brentano would have called "intentionality" is the appearance of something that does not exist within another appearance that exists. This is exactly how Brentano puts things in the 1911 Appendix. He says that the secondary presentation is the appearance (Erscheinen) of the mental phenomenon's directedness toward the sound:

The act of hearing appears to be directed toward sound (Dem Tone erscheint das Hören zugewandt) in the most proper sense of the term, and because of this it seems to apprehend itself incidentally and as something additional. (Brentano 1973: 180; Engl. trans. 128)

As I said earlier following Katalin Farkas, "intentionality" is a phenomenal relation or an "apparent directedness". Your mental act is "intentional" inasmuch as you are conscious — or you have a direct presentation - of your own present mental act and this mental act appears to have a part that does not exist. Thus, the intentional relation is an apparent mereological relation that stands between the mental act and its content. And the presentation of the 
inexistent content is an oblique presentation, because the content is the terminus of a relation. ${ }^{5}$

\section{Why the non-representational reading is better}

In conclusion, I wish to suggest some reasons for preferring the non-representational to the representational interpretation, on the basis of the two difficulties I have raised for the latter.

First, it is obvious that the intentional existence issue simply ceases to be a problem if one denies, as I did, that the secondary relation is a representation. The secondary relation consciousness, inner perception - is now described as a relation to a real object, while intentionality is a relation to an intentional object, that is, to an object that appears without existing. This resolves the contradiction I have mentioned. For the object of inner perception is no longer an intentional object. Thus it no longer needs to exist and not exist at the same time as in the self-representational interpretation.

I now turn to the second difficulty. In summary fashion: Brentano holds that every single mental act has two objects. For example, your act of seeing the color has as its objects a physical and a mental phenomenon, namely the color and itself. This is problematic because, from the representationalist perspective, this seems to imply that the color is represented twice: the color is both the intentional object of the primary representation and part of the object of the secondary representation. But as I said, Brentano firmly denies that the color is presented twice.

Of course, the self-representationalist would not agree with this. She would emphasize the fact that, for her as well as for Brentano, there is not two, but only one representation: one and the same representation has two distinct intentional objects. But then it is the plurality of objects that is problematic. For it becomes unclear why there should be a real distinction between the primary and the secondary object, and why they could not be parts of one single presented object. Why should there be two objects instead of just one? Why couldn't the color and the act of seeing be part of one single psychophysical object, as for example Mach or Carnap claimed?

My contention is that this problem, too, disappears once you opt for a non-representational reading of Brentano's theory of secondary objects. It is clear that, in the non-representational

\footnotetext{
5 "Someone who is thinking of a mental activity is, in a certain way, thinking of two objects at the same time, one of them in recto, as it were, and the other in obliquo. If I think of someone who loves flowers, then the person who loves flowers is the object I am thinking of in recto, but the flowers are what I am thinking of in obliquo." (Brentano 1925: 134; Engl. trans. 272-273) The view that the mental act has a part that is really distinct from it is problematic. Brentano distinguishes between the intentional object as the content of the act and the intentional object as its correlate.
} 
interpretation as well, the primary object is not presented twice. But what about the real distinction between mental and physical phenomena?

The key point is that, in marked contrast with the self-representational interpretation, the nonrepresentational interpretation tends to favor an intransitive view of consciousness - an intransitive view which I believe is more consistent with Brentano's statement that the mental phenomenon "is present to itself as content" (ist sich selbst als Inhalt gegenwärtig) (Brentano 1973: 180; Engl. trans. 127 modified). The idea that consciousness is not a representation clearly suggests that the identity of the mental phenomenon and its presentation or consciousness should be taken at face value - namely in the sense in which dancing a dance is not different from the dance itself. ${ }^{6}$ Dan Zahavi suggested something like this in a paper of 1998:

As a first step towards an understanding of self-awareness, it might be useful to point to the contrast between intentionality, which is characterized by a difference between the subject and the object of experience, and selfawareness which implies some form of identity. (Zahavi 1998: 128-129)

In other words, the mental phenomenon and its presentation are one and the same thing. Consciousness is not something directed toward, and superadded to, the mental phenomenon; it is no more than its being there as a phenomenon, that is, its appearing. By contrast, the physical phenomenon must be different from its presentation, for it does not really exist. If the physical phenomenon were numerically identical to its presentation, this would lead to a contradiction, namely: There exists a presentation such that it is identical to its object and that its object does not exist.

Thus, the mental phenomenon is identical with its presentation; the physical phenomenon is different from its presentation. To this we can now add Brentano's claim that the secondary and the primary presentation are identical: there is only one mental phenomenon which we decompose by abstraction into two distinct presentations. For example: one and the same thing is a pen and is on the table, although we can conceptually distinguish between that which is a pen and that which is on the table. The pen and the thing on the table are numerically identical. ${ }^{7}$

\footnotetext{
${ }^{6} \mathrm{Cf}$. Siewert 2012. On the adverbial account of phenomenal consciousness, see also Thomasson 2000; Thomas 2003; Zahavi 2004; Zahavi 2006; Seron 2015a.

${ }^{7}$ Textor (2006) denies that Brentano views the two presentations as identical. His argument runs like this: two mental acts that are different in mode cannot be numerically identical; at least some primary presentations are different in mode from their secondary presentation; therefore it is not true that every primary presentation is numerically identical with its secondary presentation. If proposition (a) is correct, then your act of rejecting a phenomenon A must be numerically identical with your inner perception of your act of rejecting A. But since the
} 
To recapitulate:

(a) The secondary presentation of the mental phenomenon is numerically identical with the (presently experienced) mental phenomenon.

(b) The primary presentation of the physical phenomenon is different from the physical phenomenon.

(c) The secondary presentation of the mental phenomenon is numerically identical with the primary presentation of the physical phenomenon.

The conjunction of these three propositions implies, by transitivity of identity, that the physical phenomenon must be different from the mental phenomenon.

This result can easily be generalized to cover the cases in which the object of the primary presentation - the intentional object - is not a physical, but a mental phenomenon. When you remember to have felt sad the day before, you have a primary presentation of your past feeling and a secondary presentation of your present remembering your past feeling (Seron 2017: 36). The remembered mental act is not presently perceived and no longer really exist. Thus, in this case as well, the present mental phenomenon is necessarily different from its intentional object. The non-present mental phenomenon that is obliquely presented must be different from the present mental phenomenon that is innerly perceived. Since every phenomenon is either mental or physical, we may safely conclude that there must be a real distinction between the present mental phenomenon and its intentional object. Now, Brentano's so-called intentionality thesis states that necessarily every (present or non-present) mental act has an intentional object. Therefore, we have demonstrated that Brentano's theory of intentionality and consciousness, if construed in non-representational terms, not only is compatible with, but entails the view that necessarily every single mental act has two really distinct objects.

To conclude with: the non-representational interpretation is better than the selfrepresentational interpretation insofar as the latter raises at least two major difficulties that the former allows to escape. First, the non-representational interpretation makes Brentano's view that the intentional object does not exist consistent with his view that the innerly perceived mental act necessarily exists. Second, the non-representational interpretation, unlike the self-

\footnotetext{
latter involves accepting your act of rejecting A, it follows from this that the whole act has two opposed modes, namely acceptance and rejection - which is obviously impossible. However, Textor's first premise strikes me as rather implausible. It would be compelling if the two presentations had the same object, but Brentano strongly denies that they do. Maybe you cannot both accept and reject A at the same time, but I don't see why you could not accept that you reject A. As Textor himself concedes, one may reply to his objection that, in the case of a desire, "the desire concerns one object, say wisdom, while the judgement is an acceptance of present desire for wisdom" (Textor 2006: 14).
} 
representational interpretation, entails a real distinction between the primary and the secondary object of the act.

\section{References}

Brentano, F. (1973). Psychologie vom empirischen Standpunkt. Hamburg: Meiner. Engl. trans. (1995). Psychology from an Empirical Standpoint (A.C. Rancurello, D.B. Terrell, \& L.L. McAlister, Trans.). London New York: Routledge.

Brentano, F. (1925). Psychologie vom empirischen Standpunkt. Vol. 2: Von der Klassifikation der psychischen Phänomene. Leipzig: Meiner. Engl. trans.: Psychology from an Empirical Standpoint (A.C. Rancurello, D.B. Terrell, \& L.L. McAlister, Trans.). London New York: Routledge.

Brentano, F. (1956). Die Lehre vom richtigen Urteil (F. Mayer-Hillebrand, Ed.). Bern: Francke.

Brentano, F. (1988). Über Ernst Machs „Erkenntnis u. Irrtum “. Mit zwei Anhängen: Kleine Schriften über E. Mach. Der Brentano-Mach-Briefwechsel, R.M. Chisholm \& J.C. Marek (Eds.). Amsterdam New York: Rodopi.

Crane, T. (2017). Brentano on intentionality. In: The Routledge Handbook of Franz Brentano and the Brentano School (U. Kriegel, Ed.). London New York: Routledge.

Farkas, K. (2013). Constructing a world for the senses. In: Phenomenal Intentionality (U. Kriegel, Ed.). Oxford: Oxford University Press, p. 99-115.

Husserl, E. (1984). Logische Untersuchungen, Vol. 2/1: Untersuchungen zur Phänomenologie und Theorie der Erkenntnis. In: Husserliana. Gesammelte Werke, Kluwer, Vol. 19/1 (U. Panzer, Ed.). Engl. trans. (2001). Logical Investigations, Vol. 2 (J.N. Findlay, Trans.). London New York: Routledge, 2001.

Kriegel, U. (2009). Self-representationalism and phenomenology. Philosophical Studies, $143 / 3$, p. $357-381$.

Kriegel, U. (2013). Brentano's most striking thesis: No representation without selfrepresentation. In: Themes from Brentano (D. Fisette \& G. Fréchette, Eds.). Amsterdam New York: Rodopi.

Russell, B. (1992). Theory of Knowledge: The 1913 Manuscript. London New York: Routledge. 
Seron, D. (2015a). Problèmes de l'auto-représentationalisme. In: Esthétique et complexité II: Neurosciences, évolution, épistémologie et philosophie (Z. Kapoula, L.-J.

Lestocart, J.-P. Allouche, Eds.). Paris: CNRS Éditions, p. 313-327.

Seron, D. (2015b). L'équivalence entre "mental” et "conscient” chez Brentano. In: Approches phénoménologiques de l'inconscient (D. Popa \& M. Gyemant, Eds.). Hildesheim Zürich New York: Olms, p. 15-36.

Seron, D. (2017). Brentano's project of descriptive psychology. In: The Routledge Handbook of Franz Brentano and the Brentano School (U. Kriegel, Ed.). New York: Routledge, p. 35-40.

Seron, D. (forthcoming). Intentionality vs. psychophysical identity. In: Ernst Mach - Life, Work, and Influence / Ernst Mach - Leben, Werk und Wirkung (F. Stadler, Ed.). Springer.

Siewert, Ch. (2012). Respecting appearances: a phenomenological approach to consciousness. In: The Oxford Handbook of Contemporary Phenomenology (D. Zahavi, Ed.). Oxford: Oxford University Press, p. 48-69.

Stout, G.F. (1896), Analytic Psychology. London: Swan Sonnenschein \& Co.

Textor, M. (2006). Brentano (and some neo-Brentanians) on inner consciousness. Dialectica, 60/4, p. 411-432.

Thomas, A. (2003). An adverbial theory of consciousness. Phenomenology and the Cognitive Sciences, 2/3, p. 161-185.

Thomasson, A. (2000). After Brentano: A one-level theory of consciousness. European Journal of Philosophy, 8/2, p. 190-209.

Zahavi, D. (1998). Brentano and Husserl on self-awareness. Études Phénoménologiques, 27/28, p. 127-168.

Zahavi, D. (2004). Back to Brentano? Journal of Consciousness Studies, 11/10-11, p. 66-87.

Zahavi, D. (2006). Two takes on a one-level account of consciousness. Psyche, 12 (2), p. 1-9. 